\title{
Effect of genotype and phenological stages on the accumulation rate of dry matter in wheat
}

\author{
Stefan M. Marković ${ }^{*}$, Desimir Knežević ${ }^{2}$ Nevena H. Djukić ${ }^{1}$ \\ ${ }^{1}$ University of Kragujevac, Faculty of Science, Radoja Domanovica 12, 34000 Kragujevac, Republic of Serbia \\ ${ }^{2}$ University of Pristina, Faculty of Agriculture, 38219, Lešak, Kosovo and Metohia, Republic of Serbia \\ *Corresponding author: Stefan M. Markovic', e-mail: stefan.markovic90@.pmf.kg.ac.rs
}

Key words: nutritional quality, wheat, genotypes, dry matter

Publication date 31/05/2020, http://m.elewa.org/Journals/about-japs/

\section{SUMMARY}

Considering that wheat occupies a primary place in human food, it is important to find varieties of wheat that, in addition to their high yields, are characterized by high nutritive and mineral qualities. The aim of this study was to determine dry matter content in genetically divergent wheat varieties, to identify varieties with a higher dry matter content, as well as to determine the accumulation rate of dry matter in different phenological phases. The highest increase in the amount of dry matter occurred in the phase of seed filling $(16.31 \%)$. The fastest accumulation of dry matter for a period of one week was recorded in the phenological phase of milk maturation. Based on the results, it was concluded that phenological phase of seed filling is an important period of the wheat development for the accumulation of dry matter. The amount of accumulated dry matter depends on the variety of wheat. Varieties with higher amount of accumulated dry matter can be possibly used for selection and hybridization.

\section{$2 \quad$ INTRODUCTION}

Dry matter of plant is the mass of a completely dry plant and represents all plant components excluding water. Approximately $70 \%$ of wheat grain dry weight is made of starch (Jaiswal et al., 2017) and includes also low protein content (Ayub et al., 2013), fats, vitamins, minerals, antioxidants and is an essential and nutritious part of the wheat. The content of grain dry matter is an important criterion for assessing the quality of cereals (Moshatati and Gharineh, 2012). The content of dry matter and the rate of accumulation, in wheat seed depends on several factors. The percentage of dry matter can depend on the genotype of plant species and the phenological phase in which the genotype is (Fisher and Fowler, 1975; Atta et al., 2004). In the booting stage, about $21 \%$ of dry matter can be found in the barley, $22 \%$ in wheat, $14 \%$ in rice and $18 \%$ in oat, while in the further development of cereals, the percentage of dry matter can increase significantly (Coskun et al.,
2014). Period of sowing (Ehdaie and Waines, 2001; Mirosavljević et al., 2018) and preceding crops (Kumar et al., 2013), can influence dry matter content in cereals. The harvest period can be also an important for accumulation of dry matter in wheat seed. A delayed period of harvest can lead to the accumulation of a larger amount of dry matter (Ayub et al., 2013). Papakosta and Gagianas (1990) have shown that for the accumulation of dry matter in wheat seed is important a period before the phenological phase of flowering and that if during this period there is a greater accumulation of dry matter, more dry matter will be transferred to the grain at later stages of the development of wheat. The amount of dry matter can also depend on the sowing method. Studies shown that the higher density of sowing leads to an increase in dry matter (Arduini et al., 2006, Fang et al., 2010). The rate of accumulation of dry matter depends on the variety of the wheat and the chemical 
characteristics of the soil (Masoni et al., 2007; Cox et al., 1985). For the accumulation of dry matter, of great importance is the amount of nitrogen (Koutroubas et al., 1998) present in the early stages of wheat development. The lack of nitrogen can reduce the amount of dry matter at later stages of development (Uhart and Andrade, 1995). In general, plant nitrogen uptake at various growth stages seemed to be more related to an increased dry matter production than to an increase in nitrogen concentrations in plants (AlKaisi and Yin, 2003). For the accumulation of dry matter also important is the method of fertilization (Dordas, 2009; Ferrise et al., 2010). To achieve a uniform accumulation of dry matter and to reduce the risk of dry matter loss, it is important to distribute fertilizer evenly and perform fertilization in divided phases (Papakosta and Gagianas, 1990). Also important is the ratio of mineral substances contained in the fertilizer. In the case of NPK fertilizers, a higher nitrogen content (24:8:16 and 31:11:11) may lead to reduction of the amount of dry matter. Higher sulphur content in fertilizer can also lead to a decrease in dry matter (Amanullah, 2017). The content and accumulation of dry matter in wheat can be greatly influenced by the temperature and quantity of water that is available to the plants ( $\mathrm{Li}$ et al., 2001). If in the development period of the wheat a significant increase in temperature occurs (Wardlaw et al., 1980) or if occurs a deficit of water, the

\section{METHODOLOGY}

3.1 Plant material and experimental conditions: In this experiment 16 varieties of genetically divergent winter wheat varieties were used (Pobeda, Simonida, Ilina, Zvezdana, Petrija, NS $40 \mathrm{~S}$, Anapurna, Andino, Nikol, Avenu, Hystar, Ratarica, Vezeljka, Merkur, Carica, Talas). The varieties were sown on an experimental plot of $10 \mathrm{~m}^{2}$ in five replicates. Sowing density was 500 kernels per $\mathrm{m}^{-2}$. Time of sowing was in October 2015 at the location of Agricultural Extension Service Kraljevo Ltd. experimental field $\left(43^{\circ} 45^{\prime} 11.5^{\prime \prime} \mathrm{N} 20^{\circ} 48^{\prime} 03.1^{\prime \prime E}\right)$. The soil type was meadow valley chernozem. Mineral fertilizer (NPK 15:15:15) was applied before sowing, in accumulation of dry matter is significantly reduced, and a disruption of the dry matter transport can be present in the plant (Plaut et al., 2004). In food production, beside to the total quantity produced, it is important to fulfill certain quality requirements, which include the ratio of energy and mineral composition, as well as the ratio of the amount of dry matter as the carrier of nutritional values and the amount of water contained in the food. Considering that the wheat occupies a primary place in everyday human and animal consumption (Filipović et al., 2003; Rađen, 2012), it is important to find varieties of wheat that, in addition to their high yields, are characterized by high nutritive and mineral qualities. The varieties that we used for research were used in Serbia agricultural production as varieties that are characterized by high yield quality. Therefore, it has been necessary to determine wheat varieties that are characterized with high nutritive and mineral qualities, which can be possibly used for selection and hybridization. The aim of this study was to determine the percentage of dry matter of seeds in 16 genetically divergent winter wheat varieties in different phenological stages, to determine effect of genotype on dry matter content, to identify varieties with a high percentage of dry matter, as well as to determine the rate of accumulation of dry matter in analyzed winter wheat varieties in different phenological stages.

accordance with the recommendations based on the chemical properties of the land and the available content of $\mathrm{P}$ (phosphorus), $\mathrm{K}$ (potassium) and $\mathrm{N}$ (nitrogen). For nutrition, fertilizers were applied on two occasions. First nutrition was carried out in the third decade of February with CAN fertilizer $\left(150 \mathrm{~kg} \mathrm{ha}^{-1}\right)$, and the second nutrition with $50 \mathrm{~kg} \mathrm{ha}{ }^{-1}$ of CAN mineral fertilizer. Adequate protection against pests and weeds was done with the appropriate use of pesticides (TEZIS $10 \mathrm{~g} \mathrm{ha}^{-1}+$ BONACA EC $0.41 \mathrm{ha}^{-1}$; AKORD $0.51 \mathrm{ha}^{-1}+$ POLUX $0.2 \mathrm{l}$ $\left.\mathrm{ha}^{-1}\right)$, under the supervision, for their effectiveness. 
Samples were collected on every seventh day in different phenological phases (seed filling phase, phase of milk development, dough development stage, ripening stage). For the analysis were collected the seed samples of different winter wheat varieties.
3.2 Climate conditions: The climatic conditions during vegetative season are shown in Table 1. During the January/June period, average air temperature values were $11.2{ }^{\circ} \mathrm{C}$, while precipitation sum was $521.2 \mathrm{~mm}$.

Table 1: Monthly and average air temperatures and monthly and cumulative values of precipitation during vegetative seasons

\begin{tabular}{|c|c|c|c|c|c|c|c|c|}
\hline \multirow[t]{2}{*}{ Period } & January & February & March & April & May & Jun & Average & Sum \\
\hline & \multicolumn{8}{|c|}{ Temperature, ${ }^{\circ} \mathrm{C}$} \\
\hline \multirow[t]{2}{*}{2016} & -0.1 & 8.8 & 7.8 & 14.1 & 15.5 & 21.3 & 11.2 & 67.4 \\
\hline & \multicolumn{8}{|c|}{ Precipitation, $\mathrm{mm}$} \\
\hline 2016 & 86.2 & 52.7 & 157.9 & 39.9 & 135.9 & 48.6 & 86.9 & 521.2 \\
\hline
\end{tabular}

3.3 Dry matter accumulation: Plants from $1 \mathrm{~m}$ row length per variety were collected randomly from the area marked for the purpose of dry matter estimation. The plant material was dried at room temperature and finally oven-dried at $70{ }^{\circ} \mathrm{C}$ to a constant weight for estimation of dry matter accumulation. Measurement of samples was carried out on an analytical balance with the accuracy of $0.0001 \mathrm{~g}$, after preliminary preparation of the samples. Based on the five independent measurements for each variety, average values were calculated, and the

\section{RESULTS}

Percentage of dry matter in analysed wheat varieties sampled in the phenological stage of seed filling, ranged from $25.28 \%$ (variety Ilina) to $41.01 \%$ (variety Andino) (Figure 1). Among analyzed varieties of winter wheat that were characterized by a higher percentage of dry matter of $35 \%$ were varieties Avenu (38.74\%), percentage of dry matter was obtained (Sharma et al. 2012).

3.4 Statistical analysis: Statistical analysis was performed using SPSS program (IBM SPSS Statistics, Version 20, Inc. 1989-2011, USA). The dry matter content in different phenological phase were subjected to a two-factor analysis of variance (ANOVA test) followed by a Fisher's LSD multiple-range test at the significance level $\mathrm{p} \leq 0.05$. Paired-samples $\mathrm{T}$ test was performed, at the significance level $p<0.05$.

NS40S (37.90\%), Anapurna (37.53\%) and Simonida (36.49\%). Among others analyzed wheat varieties, dry matter percentage was below $35 \%$. The mean value of dry matter in analyzed varieties in the phenological stage of seed filling was $32.86 \%$. 


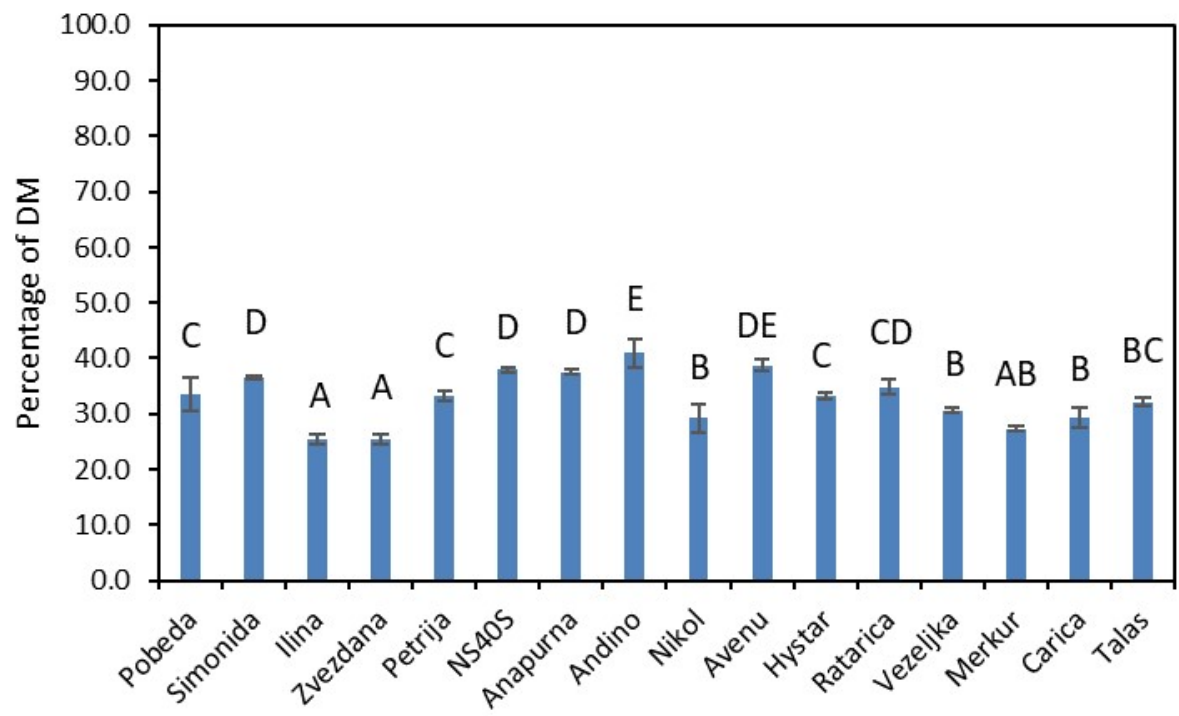

Figure 1: The amount of dry matter of wheat seed per ear, sampled in the phenological stage of seed filling expressed in percentages. Data were analyzed by two-factor ANOVA, followed by the Fisher's LSD multiplerange test. Means labelled with different letters are significantly different $(p \leq 0.05)$. DM - dry matter

Among the analysed varieties of wheat sampled in phenological phase of milk development, the accumulation of dry matter occurred, so the percentage of dry matter ranged from 36.97\% (variety Hystar) to $55.98 \%$ (variety Petrija) (Figure 2). Among analyzed varieties of winter wheat that were characterized by a higher percentage of dry matter of $50 \%$ were varieties
Anapurna (55.64\%), Simonida (54.46\%), Avenu (54.10\%), NS40S (54.04\%), Vezeljka (53.19\%), Carica (53.47\%), Andino (54.18\%), Talas $(50.76 \%)$ and Merkur (50.34\%). For other analyzed wheat varieties, the percentage of dry matter was below $50 \%$. The mean value of dry matter in analyzed varieties in the phenological phase of milk development was 50.05\%.

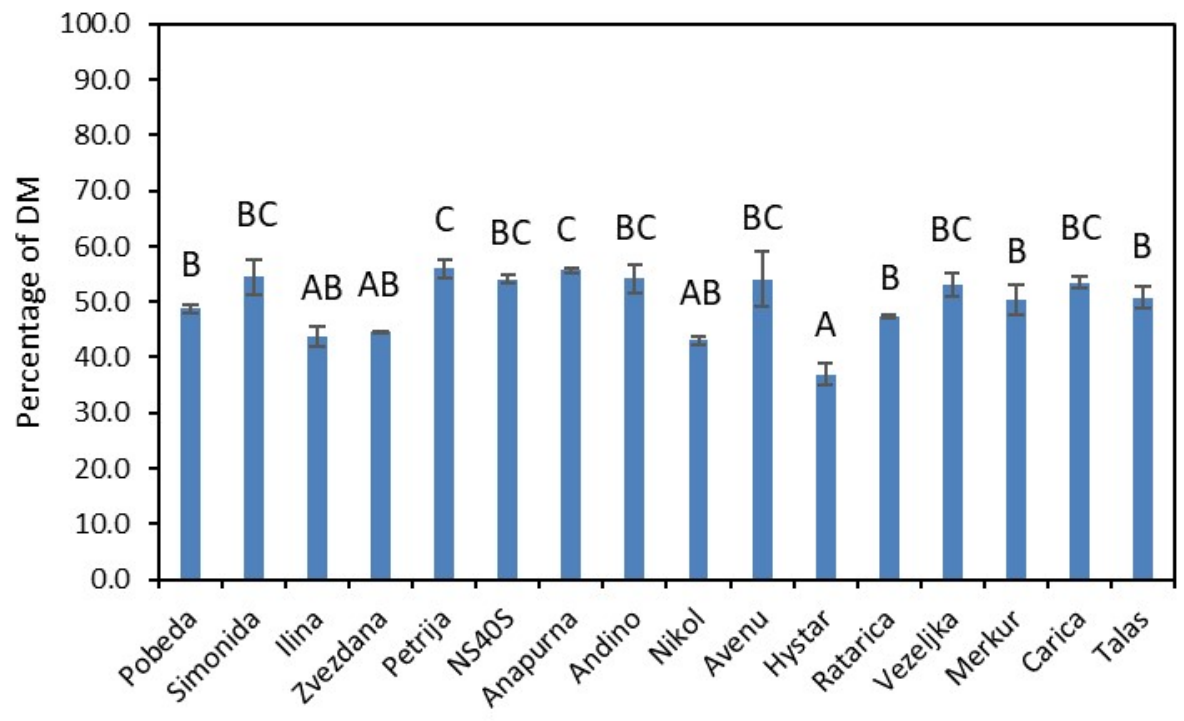

Figure 2: The amount of dry matter of wheat seed per ear, sampled in phenological phase of milk development expressed in percentage. Data were analyzed by two-factor ANOVA, followed by the Fisher's LSD multiple-range test. Means labelled with different letters are significantly different $(\mathrm{p} \leq 0.05)$. DM - dry matter 
Among the analysed wheat varieties sampled in the phenological phase of dough development, there was an increase in the percentage of dry matter ranging from $52.57 \%$ to $78.70 \%$ (Figure 3). The variety with the highest percentage of dry matter sampled in the phenological phase of dough development, 2016 was the variety NS 40 S $(78.70 \%)$, while the variety with the lowest percentage of dry matter was variety Hystar
$(52.27 \%)$. Variety that have been characterized by a dry matter content of more than $70 \%$ was the wheat variety Andino (74.29\%), Anapurna $(73.45 \%)$ and Petrija (71.19\%). Among other analyzed wheat, the percentage of dry matter was below $70 \%$. The mean value of dry matter in analyzed varieties in the phenological phase of dough development was $64.85 \%$.

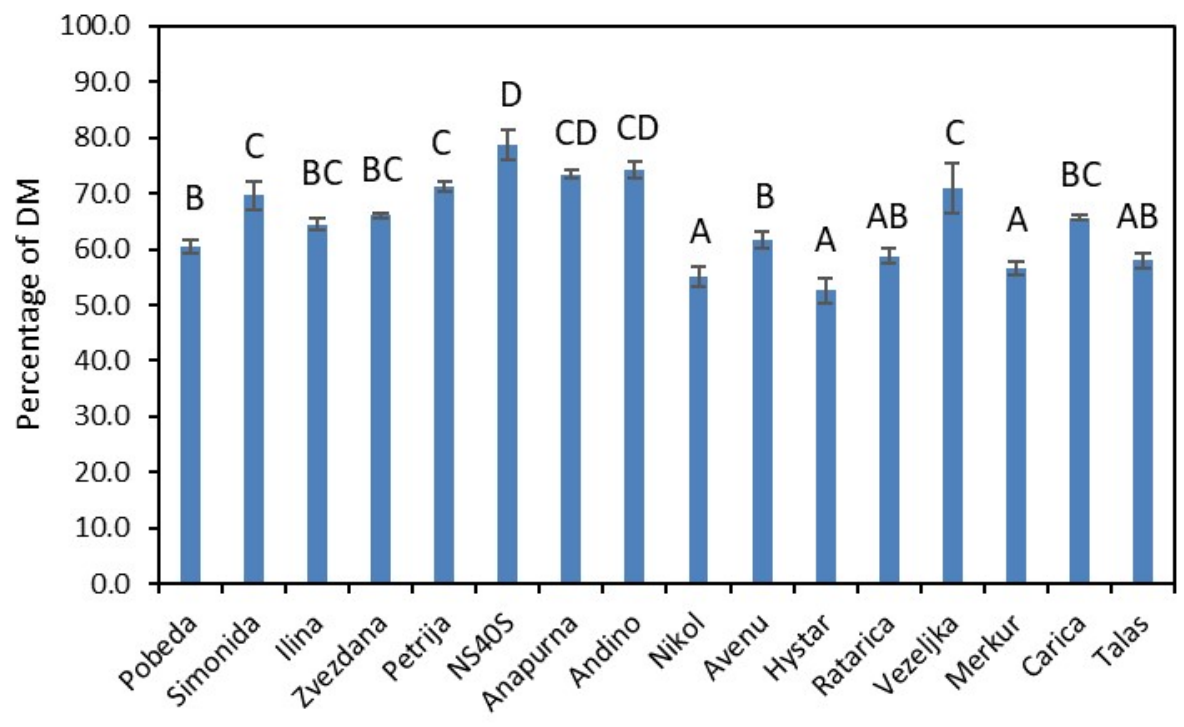

Figure 3: The amount of dry matter of wheat seed per ear, sampled in the phenological phase of dough development expressed in percentage. Data were analyzed by two-factor ANOVA, followed by the Fisher's LSD multiple-range test. Means labelled with different letters are significantly different ( $\mathrm{p} \leq 0.05)$. DM - dry matter

Among the analysed wheat varieties sampled in ripening stage, the percentage of dry matter ranged from $63.61 \%$ to $88.94 \%$ (Figure 4). Among the analyzed wheat varieties in ripening stage, the variety with the highest percentage of dry matter was variety NS 40 S (88.94\%), while the variety with the lowest percentage of dry matter was wheat variety Nikol (63.61\%).
Among the other analyzed varieties in which the percentage of dry matter was above $80 \%$ were the wheat variety Zvezdana $(86.70 \%)$, Carica (85.68\%), Petrija (85.61\%), Avenu (84.62\%), Pobeda (83.64\%) and Simonida (82.03\%). The mean value of dry matter in analyzed varieties in the phenological phase of ripening was $78.20 \%$. 


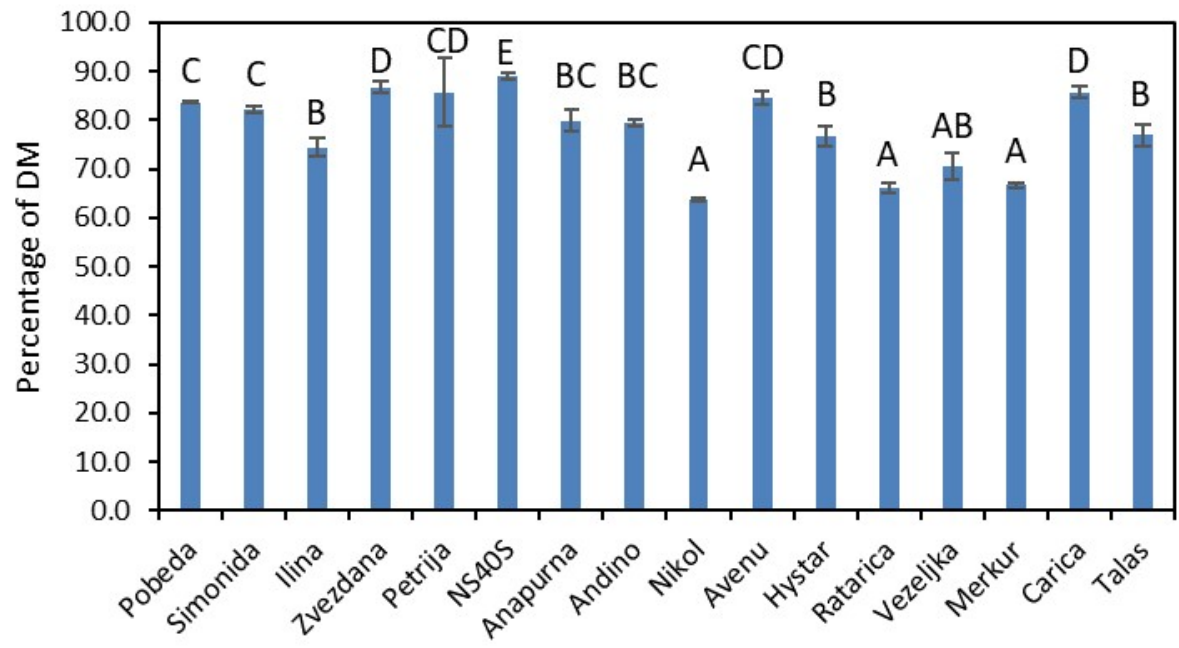

Figure 4: The amount of dry matter of wheat seed per ear, sampled in ripening stage expressed in percentage. Data were analyzed by two-factor ANOVA, followed by the Fisher's LSD multiple-range test. Means labelled with different letters are significantly different $(\mathrm{p} \leq 0.05)$. DM - dry matter

A Paired-samples T test was used, which showed that there was a statistically significant difference between dry matter content between different phenological phases of wheat development $(p<$ 0.05). Among the analysed varieties of wheat for a period from the phenological stage of seed filling to phenological phase of milk development, the highest increase in the amount of dry matter was observed in the variety Merkur where the amount of dry matter increased by $23.30 \%$, while the smallest increase in dry matter was observed in the Andino wheat variety in which the quantity of dry matter increased by only $7.28 \%$ (Figure 5 ). The average increase in the amount of dry matter in the phenological stage of seed filling was $16.31 \%$.

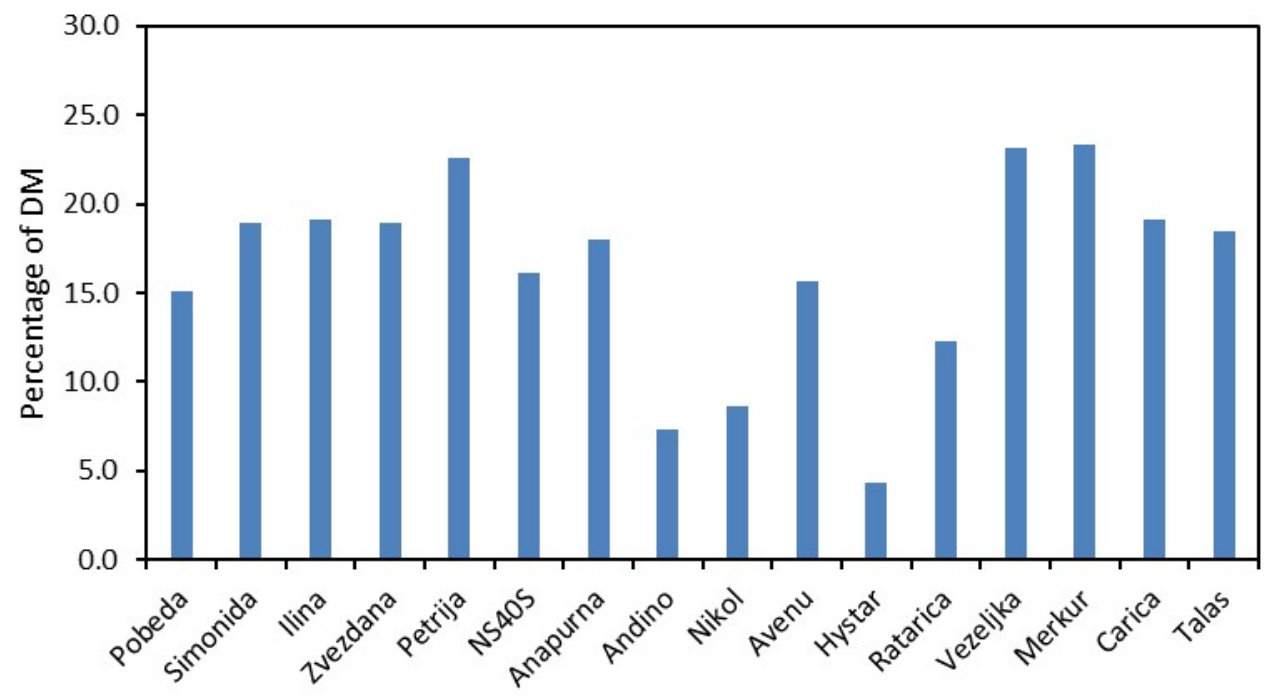

Figure 5: Change in the amount of dry matter from the phenological stage of seed filling to phenological phase of milk development 
In the period from phenological phase of milk development to phase of dough development, the largest increase in the amount of dry matter was observed in the wheat variety NS40S, with a dry matter increase by $25.39 \%$, while the lowest increase in dry matter was observed in the wheat variety Merkur, in which the amount of dry matter increased by $5.95 \%$ (Figure 6). The average increase in dry matter in the phenological phase of milk development was $14.63 \%$.

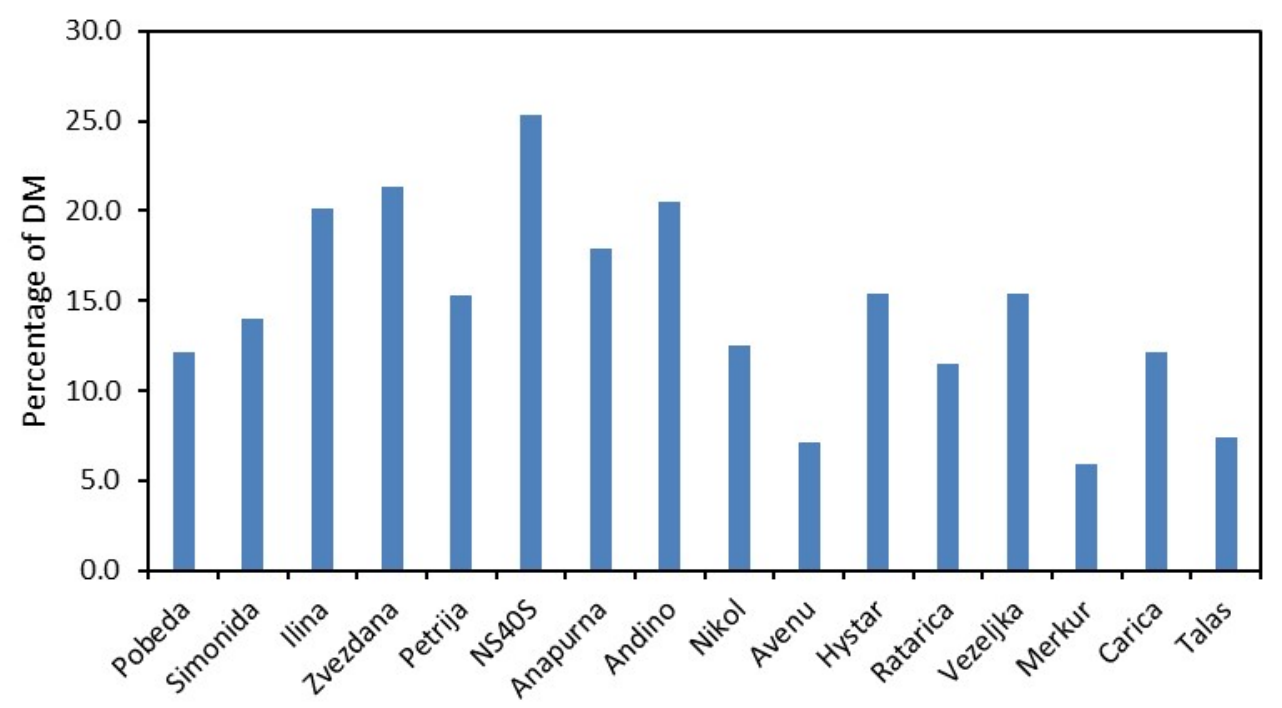

Figure 6: Change in the amount of dry matter from phenological phase of milk development to phase of dough development

In the fourth week of analysis in the period from phase of dough development to ripening stage the highest increase in dry matter content was observed in the variety of wheat Hystar $(23.60 \%)$ (Figure 7). The average increase in the amount of dry matter in the phenological phase of dough development was $13.37 \%$, while the lowest increase in dry matter was observed in the wheat variety Vezeljka $(1.79 \%)$.

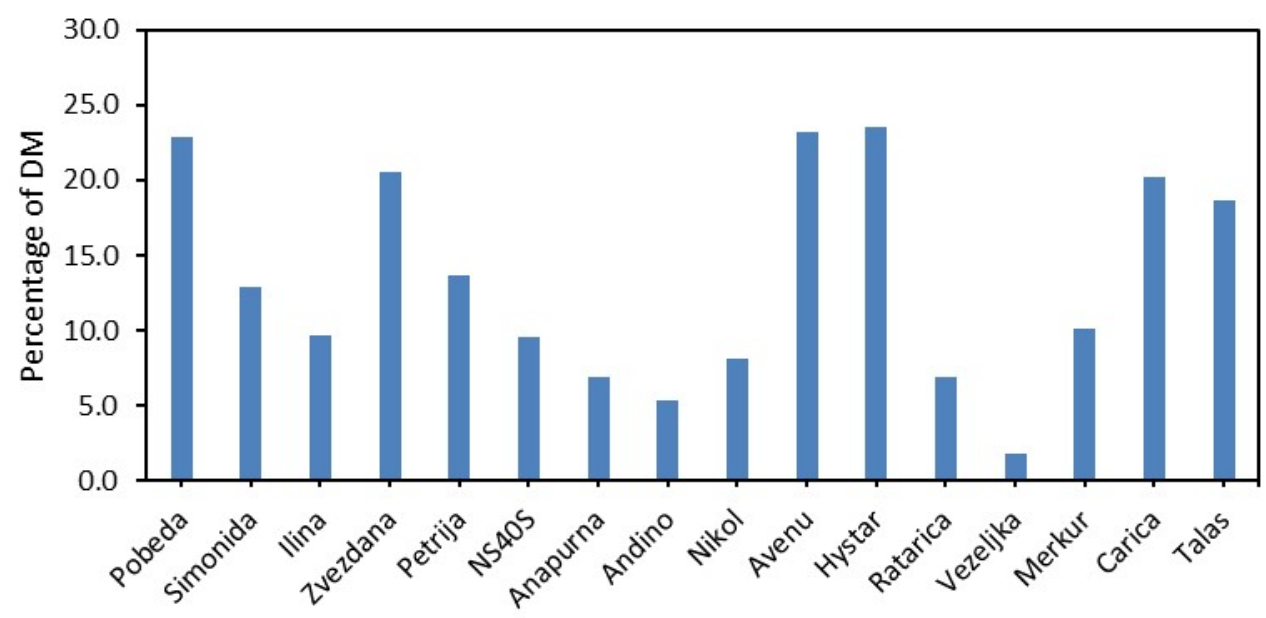

Figure 7: Change in the quantity of dry matter in varieties with a positive increase from phase of dough development to ripening stage 


\section{DISCUSSION}

During the development of wheat, in both fresh and dry weight, moisture content changes in grain (Nedeva and Nikolova, 1999). The greatest increase in the amount of dry matter occurred in the phenological phase of seed filling in which the average increase in dry matter was $16.31 \%$. In wheat variety, NS40S, in the period from the phenological stage of seed filling to phenological phase of milk development, dry matter increased by $25.39 \%$, which was the highest increase in dry matter in the period of one week compared to all other analyzed varieties. Higher increase in dry matter was observed in the variety Hystar in which in the period from phase of dough development to ripening stage, dry matter increased by $23.60 \%$. Among the analyzed varieties of wheat in the phenological stage of seed filling, the variety with the highest percentage of dry matter was the variety of wheat Andino (41.01\%), while in the stage of seed filling the mean value of dry matter in the analyzed varieties was $32.86 \%$. In the phenological phase of milk development, the variety with the highest percentage of dry matter was variety Petrija (55.98\%). In the phenological phase of the milk development, the amount of dry matter increased and reached an average value of $50.05 \%$. In the phenological phase of dough development in analyzed winter wheat varieties, the amount of dry matter continues to increase and reached an average value of $64.85 \%$.

\section{CONCLUSION}

In the production of food, in addition to the total quantity produced, it is essential to fulfil the quality requirements for which important is ratio of the quantity of dry matter as the carrier of nutritional values and the quantity of water in seed of wheat. Considering that the wheat occupies a primary place in everyday human and animal nutrition, it is important to find wheat varieties that, in addition to their high yields, feature a high percentage of dry matter. Based on the results, it can be concluded that phenological phase of seed filling is an important period of the
The variety that stands out at that stage with the highest percentage of dry matter was the variety NS40S with a dry matter of $78.70 \%$. In the phenological phase of ripening, the amount of dry matter reached its maximum when the mean value of the amount of dry matter was $78.20 \%$. In the phase of ripening, the variety with the highest percentage of dry matter was the variety NS40S (88.94\%). Numerous studies have shown that several factors can influence the amount of dry matter and the accumulation rate of dry matter. The accumulation rate of dry matter depends on the cereal variety but also from the chemical properties of the soil (Masoni et al., 2007; Cox et al., 1985), where the amount of nitrogen plays an important role (Koutroubas et al., 1998). For the accumulation rate of dry matter, the method of fertilization is also important (Dordas, 2009) as well as the ratio of mineral substances, which are found in fertilizer (Amanullah, 2017). Temperature and amount of water available to plants can be of great importance for the amount and accumulation rate of dry matter in wheat seed (Wardlaw et al., 1980; Plaut et al., 2004). Fisher and Fowler (1975) also showed that the percentage of dry matter depends on the genotype of plant species and the phenological phase in which the wheat genotype is. The harvest period is also important (Ayub et al., 2013) as well the density of sowing (Arduini et al., 2006).

wheat development for the accumulation of dry matter and that the amount of the accumulation of dry matter depends on the variety of wheat. Varieties with higher amount of accumulated dry matter can be possibly used for selection and hybridization. Based on the results of this study, we can recommend for the implementation and hybridization the varieties of winter wheat NS40S, Zvezdana, Avenu, Carica, Petrija and Pobeda as varieties with higher dry matter content. 
Acronyms and abbreviations: P (phosphorus), K (potassium), N (nitrogen), LSD (Least significant difference), DM (dry matter).

Acknowledgements: This work was supported by the Serbian Ministry of Education, Science and Technological Development.

\section{$7 \quad$ REFERENCES}

Al-Kaisi, M.M., and X. Yin. 2003. Effects of nitrogen rate, irrigation rate, and plant population on corn yield and water use efficiency. Agronomy Journal 95: 14751482.

Amanullah, K. 2017. Effects of NPK source on the dry matter partitioning in cool season $\mathrm{C}_{3}$-cereals (wheat, rye, barley, and oats) at various growth stages. Journal of Plant Nutrition 40: 352-364.

Arduini, I., A. Masoni, L. Ercoli, and M. Mariotti. 2006. Grain yield, and dry matter and nitrogen accumulation and remobilization in durum wheat as affected by variety and seeding rate. European Journal of Agronomy 25: 309318.

Atta, S., S. Maltese, and R. Cousin. 2004. Protein content and dry weight of seeds from various pea genotypes. EDP Sciences 24(5): 257-266.

Ayub, M., H. Abbas, M. Tariq, M. Tahir, M.A. Nadeem, and M.H. Siddiqui. 2013. Periodic assessment of dry matter production and nutritional value of millet legumes mix fodder. Agricultural Research 2: 265-269

Coskun, B., G. Keles, F Inal, S. Ates, and M.S. Alatas. 2014. Dry matter production and nutritive value of cereal species harvested at boot or dough stage of maturity. Animal Science 57: 85-89.

Cox, M.C., C.O. Qualset, and D.W. Rains. 1985. Genetic variation for nitrogen assimilation and translocation in wheat. I. Dry Matter and Nitrogen Accumulation. Crop Science 25: 430-435.

Dordas, C. 2009. Dry matter, nitrogen and phosphorus accumulation, partitioning and remobilization as affected by $\mathrm{N}$ and $\mathrm{P}$ fertilization and source-sink relations.
European Journal of Agronomy 30: 129139.

Ehdaie, B. and J. Gwaines. 2017. Sowing date and nitrogen rate effects on dry matter and nitrogen partitioning in bread and durum wheat. Field Crops Research 3(1): 47-61.

Fang, Y., B. Xu, N.C. Turner, and F. Li. 2010. Grain yield, dry matter accumulation and remobilization, and root respiration in winter wheat as affected by seeding rate and root pruning. European Journal of Agronomy 33(4): 257-266.

Ferrise R., A. Triossia, P. Stratonovitch, M. Bindi, and Martre, P. 2010. Sowing date and nitrogen fertilisation effects on dry matter and nitrogen dynamics for durum wheat: An experimental and simulation study. Field Crops Research 117(2-3): 245-257.

Filipović, S., M. Sakač, M. Ristić, Š. Kormanjoš, S. Galić, and S. Ivanišević. 2003. Termički postupci obrade žitarica. Journal on Processing and Energy in Agriculture 7: 3-7

Fisher, LJ. and D.B. Fowler. 1975. Predicted forage value of whole plant cereals. Canadian Journal of Plant Science 55: 975-986.

Jaiswal, B., S. Prasad, R. Dwivedi, S. Singh, R. Rani, S. Shrivastava, A. Kumar, and R.K. Yadav. 2017. Study of yield and yield components of wheat (Triticum aestivum L.) genotypes at grain filling stage under heat regimes. International journal of pure and applied bioscience 5 (4): 331340.

Koutroubas, S.D., D.K. Papakosta, and A.A. Gagianas. 1998. The importance of early dry matter and nitrogen accumulation in 
soybean yield. European Journal of Agronomy 9: 1-10.

Kumar, S., A.S. Dhindwal, and R.K. Arya. 2013. Dry matter and straw yield in wheat as influenced by preceding crops, planting methods and irrigation levels. Forage Research 39(2): 88-92.

Li, F., X Liu, and S. Li. 2001. Effects of early soil water distribution on the dry matter partition between roots and shoots of winter wheat. Agricultural Water Management 49(3): 163-171.

Masoni, A., L. Ercoli, M. Mariotti and I. Arduini. 2007. Post-anthesis accumulation and remobilization of dry matter, nitrogen and phosphorus in durum wheat as affected by soil type. European Journal of Agronomy 26: 179-186.

Mirosavljević, M., V. Momcilovic, N. Przulj, L. Maksimovic, and M. Putnik-Delic. 2018. Dry matter accumulation of winter wheat and barley at different sowing dates. Ratarstvo i povrtarstvo 55(2): 87-94.

Moshatati, A. and M.H. Gharineh. 2012. Effect of grain weight on germination and seed vigor of wheat. International Journal of Agriculture and Crop Sciences 4(8): 458460.

Nedeva, D. and A. Nikolova. 1999. Fresh and dry weight changes and germination capacity of natural or premature desiccated developing wheat seeds. Bulgarian Journal of Plant Physiology 25(1-2): 3-15.

Papakosta, D.K. and A.A. Gagianas. 1990. Nitrogen and dry matter accumulation, remobilization, and losses for mediterranean wheat during grain filling. Agronomy Journal 83: 864-870.

Plaut, Z., B.J. Butow, C.S. Blumenthal, and C.W. Wrigley. 2004. Transport of dry matter into developing wheat kernels and its contribution to grain yield under postanthesis water deficit and elevated temperature. Field Crops Research 86: 185-198.
Rađen, S. 2012. Ishrana - uloga u unapređenju zdravlja i prevenciji bolesti. Medija centar "Odbrana", Beograd, p. 103-113.

Sharma, N.K., R.J. Singh, and K. Kumar. 2012. Dry matter accumulation and nutrient uptake by wheat (Triticum aestivum L.) under poplar (Populus deltoides) Based Agroforestry System. International Scholarly Research Notices 359-673.

Uhart, S.A. and F.H. Andrade. 1995. Nitrogen defeciency in maize: i. effects on crop growth, development, dry matter partitioning, and kernel set. Crop Science 35: 1376-1383.

Wardlaw, I.F., I. Sofield, and P.M. Cartwright. 1980. Factors limiting the rate of dry matter accumulation in the grain of wheat grown at high temperature. Australian Journal of Plant Physiology 7: 387-400. 